\title{
Respiratory Changes in the Superior Vena Cava Area on Inspiratory and Expiratory Chest CT: Comparison between Patients with COPD and with Bronchial Asthma
}

\author{
Akiyuki Kotoku1, Shin Matsuoka1, Tsuneo Yamashiro',2, Shoichiro Matsushita1, Atsuko Fujikawa', \\ Hayato Tomita ${ }^{1}$, Kunihiro Yagihashi', Yasuo Nakajima ${ }^{1}$
}

\author{
${ }^{1}$ Department of Radiology, St. Marianna University School of Medicine, Kawasaki City, Japan \\ ${ }^{2}$ Department of Radiology, Graduate School of Medical Science, University of the Ryukyus, Nishihara Town, Japan \\ Email:27.akiyuki@gmail.com
}

How to cite this paper: Kotoku, A., Matsuoka, S., Yamashiro, T., Matsushita, S., Fujikawa, A., Tomita, H., Yagihashi, K. and Nakajima, Y. (2016) Respiratory Changes in the Superior Vena Cava Area on Inspiratory and Expiratory Chest CT: Comparison between Patients with COPD and with Bronchial Asthma. Open Journal of Medical Imaging, 6, 123-134.

http://dx.doi.org/10.4236/ojmi.2016.64012

Received: September 20, 2016

Accepted: December 11, 2016

Published: December 14, 2016

Copyright $\odot 2016$ by authors and Scientific Research Publishing Inc. This work is licensed under the Creative Commons Attribution International License (CC BY 4.0).

http://creativecommons.org/licenses/by/4.0/

(c) † Open Access

\section{Abstract}

Purpose: In patients with obstructive lung diseases, alteration of intrathoracic pressure is closely related to hyperinflation and leads to hemodynamic impairments. Both intrathoracic pressure and hemodynamics are affected by the respiratory phase. In fact, a previous study showed that respiratory phasic variations in the superior vena cava (SVC) area significantly correlated with the extent of emphysema. Chronic obstructive pulmonary disease (COPD) and bronchial asthma manifest different pathophysiological changes in hyperinflation and hemodynamics. The current study was conducted to evaluate differences in respiratory variations in the cross-sectional area of the SVC between patients with COPD and with asthma. Materials and Methods: We measured the SVC area and calculated the ratio of the SVC area on inspiratory and expiratory scans (i/e-SVC ratio) in 66 patients with COPD and 16 patients with asthma. The correlations of the i/e-SVC ratios with airflow limitation, pulmonary small vessels less than $5 \mathrm{~mm}^{2}(\%$ cross-sectional area $[\% \mathrm{CSA}]<5)$, and respiratory changes in lung volume (i/e-LV) obtained by inspiratory and expiratory computed tomography (CT) images were evaluated. Results: There was no significant difference in i/e-SVC ratio between COPD and asthma groups. In COPD patients, the i/e-SVC ratio significantly correlated with the $\%$ CSA $<5(\rho=-0.433, P=0.003)$, i/e-LV ratio $(\rho=-0.371, P=0.011)$, and percent of predicted forced expiratory volume in 1 second $\left(\mathrm{FEV}_{1} \%\right.$ predicted) $(\rho=-0.474, P=0.001)$, whereas in asthma patients, there were no significant correlations between the i/e-SVC ratio and those functional parameters. Conclusion: There would be differences in the relationship between intrathoracic pressure and cardiopulmonary hemodynamics between COPD 
and asthma patients.

\section{Keywords}

Computed Tomography, Hyperinflation, Hemodynamics, Intrathoracic Pressure, Expiration, COPD, Asthma

\section{Introduction}

Obstructive lung disease is characterized by airway obstruction. Airway obstruction causes pulmonary hyperinflation, which can lead to an increase in intrathoracic pressure [1] [2]. Airway obstruction is also linked to an alteration in cardiopulmonary hemodynamics because pulmonary vascular alterations are related to airway obstruction [3] [4] [5] [6] and decreased pulmonary blood flow, which leads to pulmonary hypertension. Hyperinflation increases intrathoracic pressure, which leads to excessive venous pressure with a reduction in venous return and right heart filling and subsequent decreased right ventricular output [7]. Hyperinflation also has significant adverse effects on left ventricular performance [8] [9] [10] [11].

In general, venous return is affected by intrathoracic pressure and cardiac function. The major causes of changes in venous return are changes in right atrial pressure following changes in intrathoracic pressure [12] [13]. Furthermore, the respiratory cycle is strongly associated with variations in venous return, which are mainly due to respiratory phasic variations in intrathoracic pressure [14]. Caval diameter reduction during inspiration is felt to be due to falling intrathoracic pressure and vessel collapse due to the increase in differences in transmural pressure [15]. Alterations in intrathoracic pressure during the respiratory cycle can affect the diameter and flow velocity in the proximal major veins [16] [17] [18]. In patients with emphysema, increased intrathoracic pressure has been shown to affect respiratory phasic variations in the inferior vena cava (IVC) [1]. A recent study has shown that respiratory phasic variations of the superior vena cava (SVC) area measured using paired inspiratory and expiratory computed tomography (CT) decreased as the extent of emphysema increased [19]. In addition, there was also a significant correlation between the respiratory changes in the SVC dimension and airflow limitation, although this correlation was not as strong as the extent of emphysema [19].

Bronchial asthma is also categorized as an obstructive lung disease, which causes airflow limitation and hyperinflation similarly to chronic obstructive pulmonary disease (COPD). However, in contrast to COPD, it is considered that marked alteration in cardiopulmonary hemodynamics does not occur in patients with asthma. If the physiological difference in hemodynamics between asthma and COPD truly exists, this may be reflected as a difference in respiratory movement of the SVC measured by combined inspiratory and expiratory CT scans. Thus, the aim of this study was: 1) to evaluate respiratory variations in the SVC area and its correlation to physiological parameters in 
patients with COPD and in those with asthma, and 2) to investigate the difference in these hemodynamic measurements between the COPD and asthma groups.

\section{Materials and Methods}

\subsection{Subjects}

This retrospective study was approved by our institutional review board, which waived the need for informed consent. One radiologist reviewed medical records and CT images obtained between October 2012 and July 2013, and identified patients who had a clinical diagnosis of mild/moderate COPD or bronchial asthma and had undergone inspiratory/expiratory CT scans and pulmonary function tests (PFT).

Exclusion criteria included prior cardiopulmonary disease, abnormal pulmonary lesions other than emphysema and bronchial asthma, pneumothorax, extensive pleural effusions, image noise that prevented image analysis, and lack of volume data. Subjects with acute exacerbation of COPD and status asthmaticus were also excluded.

Eventually, 64 COPD patients ( 8 women and 56 men; mean age, 72 years; age range, 55 - 88 years) and 16 bronchial asthma patients (7 women and 9 men; mean age, 70 years; age range, 61 - 80 years) were analyzed in this study. Characteristics of the patients, including results of PFT, are presented in Table 1.

\subsection{CT Scanning}

All patients were scanned with a 64-detector CT scanner (Aquilion ${ }^{\mathrm{Tm}} 64$, Toshiba Medical Systems Corp., Otawara, Tochigi, Japan). CT scanning was done during breath-hold, in both deep-end inspiration, and in deep-end expiration, with the patient in the supine position. Every patient was carefully instructed on how to breathe before the scan. CT scan parameters for both scans were as follows: collimation, $0.5 \mathrm{~mm} ; 120 \mathrm{kV} ; 200 \mathrm{~mA}$ (inspiratory scan) and $80 \mathrm{~mA}$ (expiratory scan); gantry rotation time, $0.5 \mathrm{~s}$; beam pitch,

Table 1. Demographics, pulmonary function, and CT measurements.

\begin{tabular}{cccc}
\hline & Asthma & COPD & $P$ value \\
\hline Age (y) & $70.5 \pm 6.7$ & $72.8 \pm 8.0$ & 0.221 \\
Gender, \% female (\%) & 43.8 & 12.5 & - \\
BMI & $24.6 \pm 3.2$ & $22.4 \pm 3.1$ & 0.012 \\
Pack-years & $41.0 \pm 35.1$ & $64.5 \pm 51.1$ & 0.069 \\
FEV1 (\% predicted) & $79.5 \pm 23.1$ & $76.5 \pm 18.7$ & 0.779 \\
i/e-SVC ratio & $0.71 \pm 0.15$ & $0.71 \pm 0.15$ & 0.979 \\
\%CSA $<5$ (\%) & $1.34 \pm 0.29$ & $0.68 \pm 0.19$ & $<0.001^{*}$ \\
i/e-LV ratio & $1.49 \pm 0.27$ & $1.45 \pm 0.26$ & 0.550 \\
\hline
\end{tabular}

Definition of abbreviations: $\mathrm{SD}=$ standard deviation; $\mathrm{BMI}=$ body mass index; $\mathrm{FEV}_{1}=$ forced expiratory volume in 1 second; i/e-SVC ratio = the area of SVC on inspiratory scan/the area of SVC on expiratory scan; \%LAA = percentage of low attenuation area; $\mathrm{i} / \mathrm{e}-\mathrm{LV}$ ratio $=$ lung volume on inspiratory scan/lung volume on expiratory scan; $\% \mathrm{CSA}<5=$ percentage of total lung area taken up by the cross sectional area of pulmonary vessels less than $5 \mathrm{~mm}^{2}$. 
0.83 (helical pitch, 53), respectively. All images were reconstructed using a standard reconstruction algorithm with a slice thickness of $1 \mathrm{~mm}$ and a reconstruction interval of $0.5 \mathrm{~mm}$. A voxel size was $0.625 \times 0.625 \times 1 \mathrm{~mm}$.

\subsection{CT Measurements}

The reconstructed images were transferred to a commercially available workstation (Ziostation $^{\mathrm{rw}}$, Ziosoft ${ }^{\oplus}$ Inc., Tokyo, Japan). CT measurement of the SVC area has been described elsewhere [20]. In brief, the following procedures were performed: The section scanned at the level of the tracheal carina was used to measure the SVC area. The area of the SVC was calculated from the region of interest that was traced manually on the SVC on both inspiratory and expiratory scans (Figure 1). All measurements were performed 3 times, and mean values were used for analysis. To evaluate respiratory phasic variations, the ratio of the SVC area on the inspiratory and expiratory scans was calculated as follows: i/e-SVC ratio = area of the SVC on inspiratory scan/area of the SVC on expiratory scan.

The same workstation used for CT measurements, which can isolate lung volumes with any threshold value, was used to obtain whole-lung volumes with attenuation values of -500 to -1024 Hounsfield units (HU) on inspiratory and expiratory scans. For the evaluation of hyperinflation [21], respiratory changes in lung volume were calculated as follows: i/e-LV ratio = whole-lung volume on inspiratory scan/whole-lung volume on expiratory scan.

To evaluate pulmonary small vascular components, a percentage of the crosssectional area of pulmonary small vessels $(\% \mathrm{CSA}<5)$ was obtained. CT measurement of $\% \mathrm{CSA}<5$ has been described elsewhere [22]. In brief, the following procedures were performed: First, the lung field was segmented using a threshold technique with all pixels between -500 and $-1024 \mathrm{HU}$ on each CT image. Next, segmented images were converted into binary images with a window level of $-720 \mathrm{HU}$. On the binary images, we measured the cross-sectional area of small pulmonary vessels that were per-pendicular to the images and less than $5 \mathrm{~mm}^{2}$ in dimension. We totaled the crosssectional areas of the vessels from all images, and \%CSA $<5$ was calculated by dividing the total cross-sectional areas of the vessels by the total lung areas.

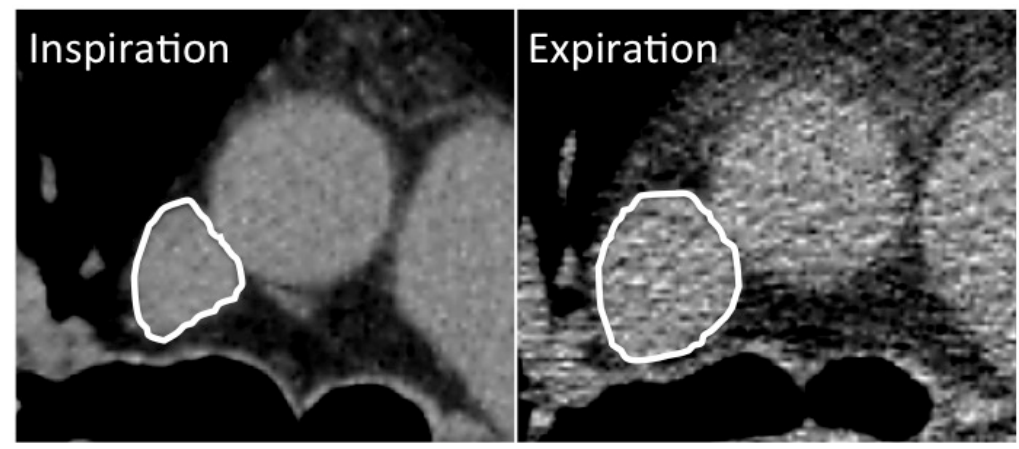

Figure 1. The inspiratory and expiratory SVC areas are measured using CT images. 


\subsection{Pulmonary Function Tests}

In this cohort, all patients underwent PFT within one month of obtaining CT scans. Forced expiratory volume in 1 second $\left(\mathrm{FEV}_{1}\right)$ was measured according to standard techniques, and $\mathrm{FEV}_{1}$ measurements were expressed as percentages of predicted values.

\subsection{Statistical Analysis}

We used the Wilcoxon rank-sum test to evaluate the differences in i/e-SVC, \%CSA $<5$, $\mathrm{i} / \mathrm{e}-\mathrm{LV}$, and results of PFTs between COPD and asthma groups. Spearman rank correlation coefficients were used for the evaluation of correlations of i/e-SVC with \%CSA $<5$, $\mathrm{i} / \mathrm{e}-\mathrm{LV}$, and PFT. The results are summarized in Table 2. Data are expressed as the mean \pm standard deviation for all continuous variables. For all statistical analyses, the null hypothesis was rejected at the $5 \%$ level. All statistical analyses were performed using JMP ${ }^{\circledast}$ Version 8.0 (SAS Institute Inc., Cary, NC).

\section{Results}

\section{CT Measurements and Correlations with SVC}

Results of CT measurements are shown in Table 1. Mean i/e-SVC ratios were $0.71 \pm$ 0.15 in patients with COPD and $0.71 \pm 0.15$ in patients with asthma. There was no significant difference in i/e-SVC ratio (Figure 2(a)), i/e-LV (Figure $2(\mathrm{c})$ ), and $\mathrm{FEV}_{1} \%$ predicted (Figure 2(d)) between COPD and asthma groups $(P=0.979,0.550$, and 0.779 , respectively). Meanwhile, the $\% \mathrm{CSA}<5$ in COPD group was significantly smaller than that in asthma group $(P<0.0001)$ (Figure $2(\mathrm{~b}))$.

The correlations of the i/e-SVC ratio with \%CSA $<5$, i/e-LV change, and FEV1\% predicted are shown in Figure 1. In COPD penitents, the i/e-SVC ratio had significant correlations with the \%CSA $<5$ ( $\rho=-0.433, P=0.003$ ) (Figure 3(a) left side), i/e-LV ratio $\left(\rho=-0.371, P=0.011\right.$ ) (Figure 3 (b) left side), and $\mathrm{FEV}_{1} \%$ predicted $(\rho=-0.474$, $P=0.001$ ) (Figure 3(c) left side), whereas in asthma patients there were no significant correlations between the $\mathrm{i} / \mathrm{e}-\mathrm{SVC}$ ratio and the $\% \mathrm{CSA}<5(\rho=0.334, P=0.162)$ (Figure 3 (a) right side), $\mathrm{i} / \mathrm{e}-\mathrm{LV}$ ratio $\left(\rho=-0.252, P=0.313\right.$ ) (Figure $3(\mathrm{~b})$ right side), or $\mathrm{FEV}_{1} \%$ predicted $(\rho=-0.085, P=0.701)$ (Figure $3(\mathrm{c})$ right side).

Table 2. Correlations between i/e-SVC and functional parameters.

\begin{tabular}{ccccc}
\hline & \multicolumn{3}{c}{ Asthma } & \multicolumn{2}{c}{ COPD } \\
\cline { 2 - 5 } & $\rho$ & $P$ & -0.433 & 0.003 \\
\hline \%CSA $<5(\%)$ & 0.334 & 0.162 & -0.371 & 0.011 \\
i/e-LV ratio & -0.252 & 0.313 & -0.474 & 0.001 \\
FEV1\% predicted & -0.085 & 0.701 & & $P$ \\
\hline
\end{tabular}

Definition of abbreviations: i/e-SVC ratio $=$ the area of SVC on inspiratory scan/the area of SVC on expiratory scan; \%LAA = percentage of low attenuation area; i/e-LV ratio = lung volume on inspiratory scan/lung volume on expiratory scan; $\%$ CSA $<5=$ percentage of total lung area taken up by the cross sectional area of pulmonary vessels less than $5 \mathrm{~mm}^{2}$. 


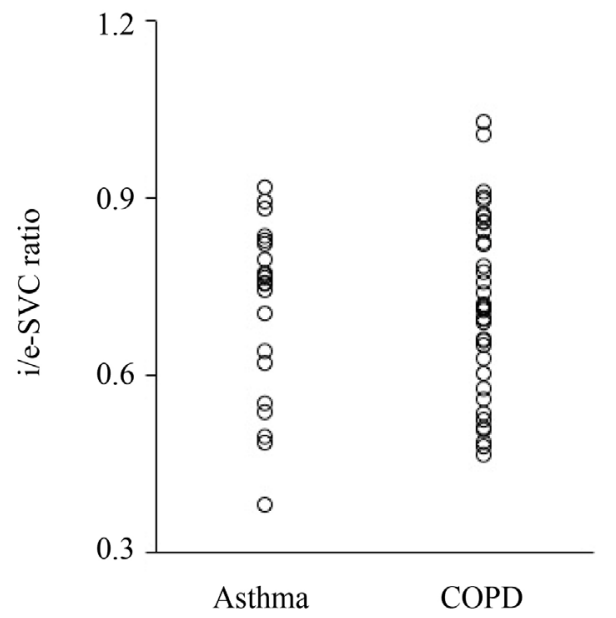

(a)

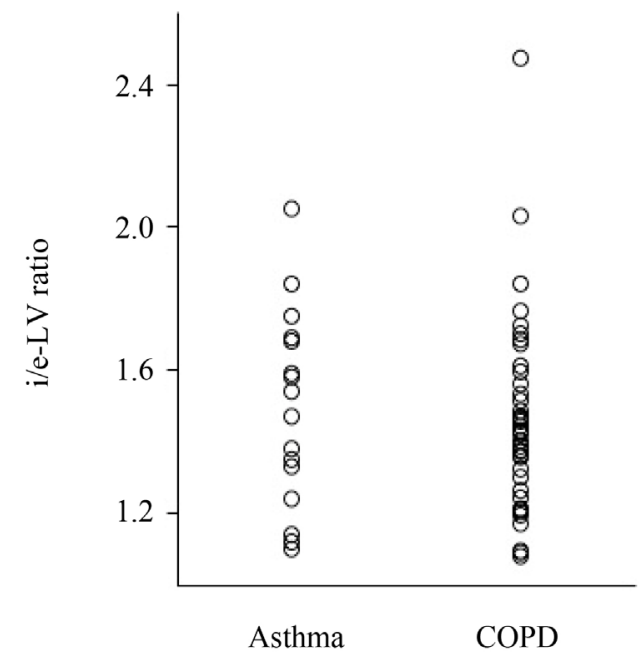

(c)

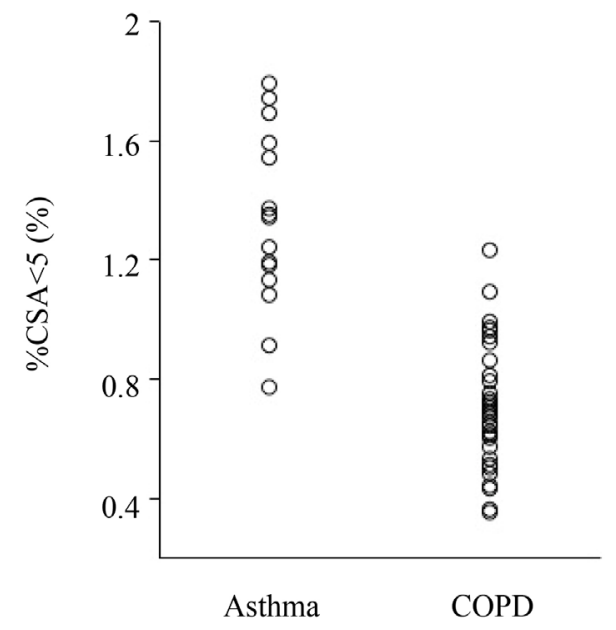

(b)

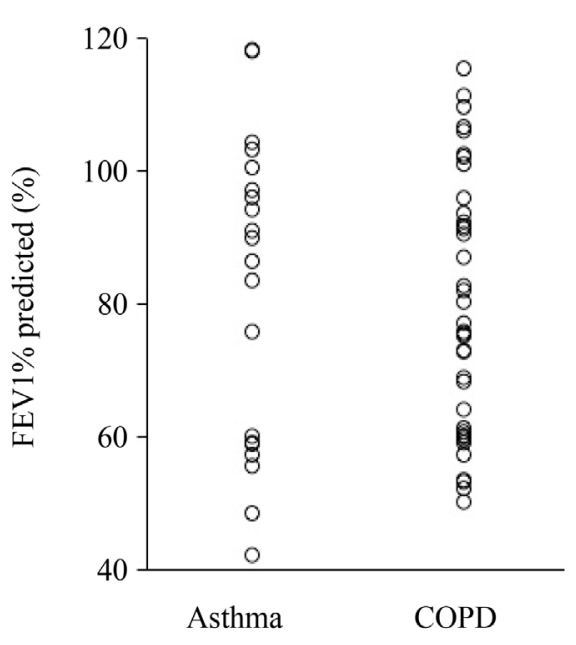

(d)

Figure 2. (a) Difference in i/e-SVC ratio between in subjects with asthma and COPD. No significant difference was found $(P=0.979)$. (b) Difference in $\%$ CSA $<5$ between in subjects with asthma and those with COPD. The \%CSA $<5$ was significantly higher in subjects with asthma than in subjects with COPD $(P<0.001)$. (c) Difference in $\mathrm{i} / \mathrm{e}-\mathrm{LV}$ ratio between subjects with asthma versus those with COPD. No significant difference was found $(P=0.550)$. (d) Difference in FEV1 (\% predicted) between subjects with asthma versus those with COPD. No significant difference was found $(P=0.779)$.

\section{Discussion}

The present study shows that, even there is no significant difference in respiratory vari ations in the SVC area or other physiological parameters between COPD and asthma groups, these respiratory changes in SVC area were significantly correlated with airflow limitation, \%CSA $<5$, and i/e-LV ratio in patients with COPD, whereas no significant correlations in patients with asthma. These findings suggest that respiratory variation in the SVC area in COPD would relate to both intrathoracic pressure and cardiopulmonary hemodynamics, which cannot be seen in bronchial asthma. 
Asthma

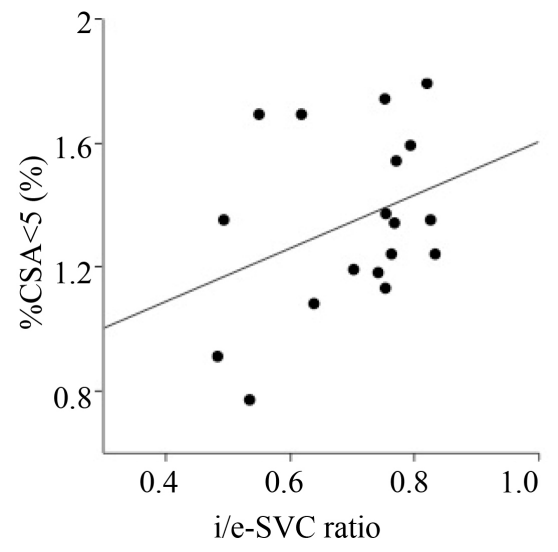

(a)
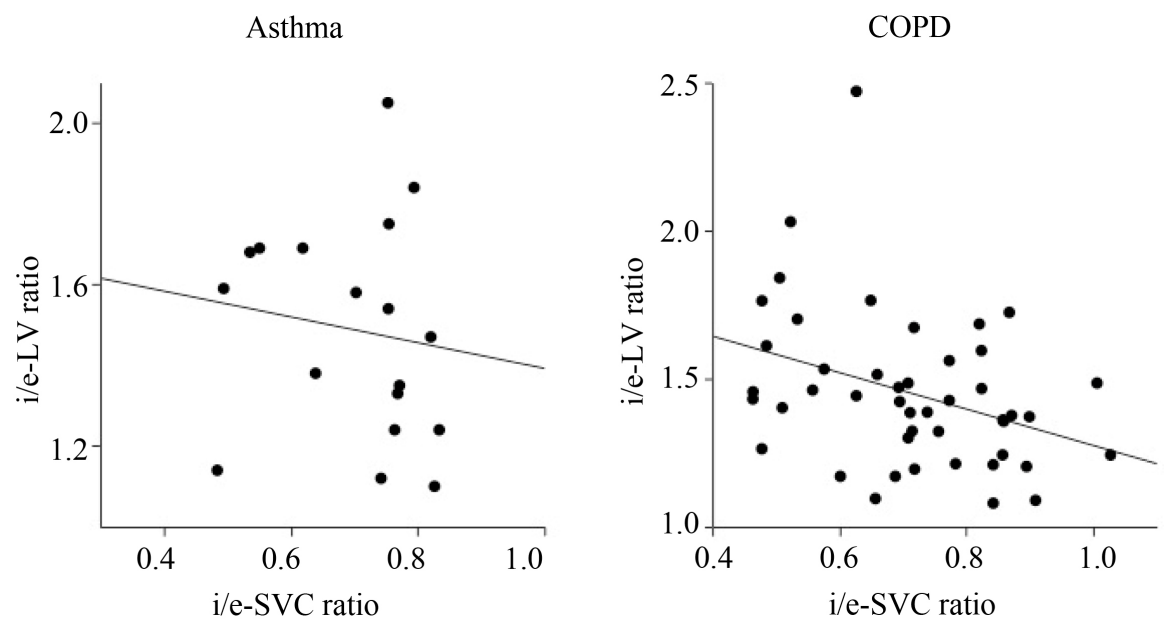

(b)

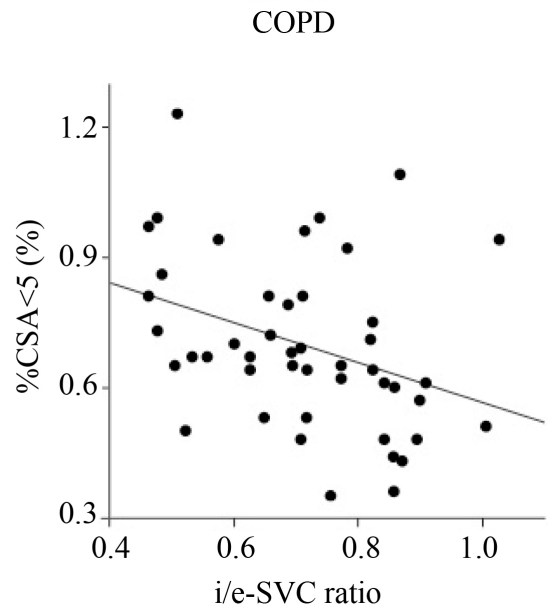

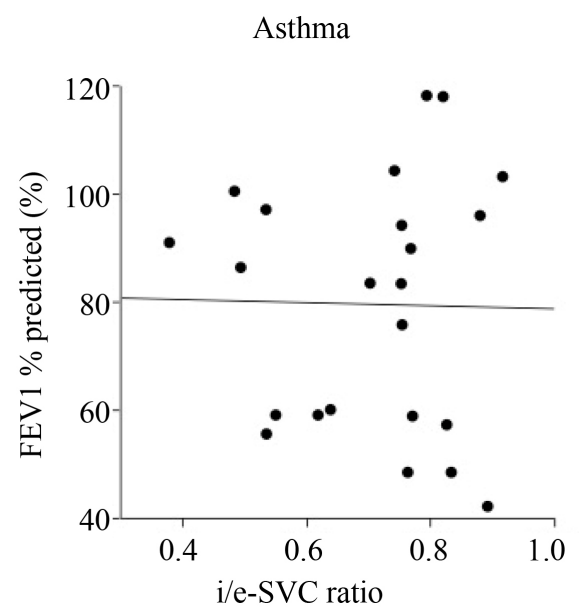

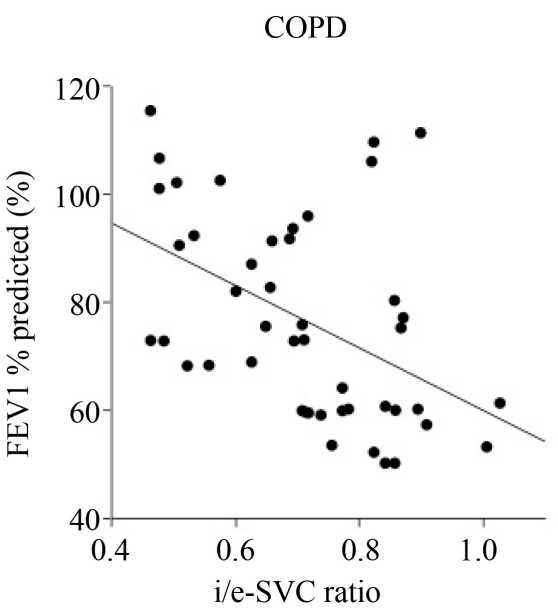

(c)

Figure 3. The relationship between the ratio of the SVC area on inspiratory and expiratory scans (i/e-SVC ratio) and (a) the percentage of the area taken up by the cross-sectional area of the pulmonary vessels smaller than $5 \mathrm{~mm}^{2}(\% \mathrm{CSA}<5)$, (b) respiratory change of lung volume (i/e-LV ratio), (c) FEV1 (\% predicted). 
In healthy subjects, negative intrathoracic pressure is enhanced during inspiration [20], and this negative pressure leads to dilation of the right cardiac chamber. Thus, venous pressure in the SVC is decreased under these conditions [8] [17]. In consequence, venous return is increased [23] [24], while simultaneously, the blood is more likely to flow into the right cardiac chambers extended by negative intrathoracic pressure, and as a result, the central vein begins to collapse [16] [17] [18]. Meanwhile, during expiration, intrathoracic pressure increases [20]. This rise in intrathoracic pressure increases the venous pressure without a significant decline in blood volume [25] [26], which leads to the dilatation of the central vein.

In patients with emphysema, diminished elastic recoil and low maximal transpulmonary pressures at total lung capacity develop [23]. The decreased distending pressures are likely related to hyperinflation, decreasing the resting length of the respiratory muscles and reducing their capacity to lower intrathoracic pressure [2]. Under the condition of insufficient negative intrathoracic pressure, the right cardiac chambers cannot dilate sufficiently, and therefore, venous pressure is not decreased. Furthermore, in COPD patients with pulmonary hypertension, both right ventricular preload and afterload increase [27]. Meanwhile, intrathoracic pressure is increased during expiration, and often turns to positive pressure, which leads to an impairment of venous return and blood filling the right cardiac chambers in combination with a decline in blood volume [1] [28]. Therefore, the central vein does not dilate sufficiently, and in patients with severe emphysema, it is plausible that these mechanisms prevent the collapse of the central vein during inspiration compared with normal subjects. In fact, one previous study showed that the i/e-SVC ratio had a significant positive correlation with the maximal percent low attenuation area (\%LA), and this study also suggested that emphysema is related to alterations of intrathoracic pressure and cardiopulmonary hemodynamics. In the current study, even in patients with mild and moderate COPD, i/eSVC ratio significantly correlates with $\% \mathrm{CSA}<5$, i/e-LV, and airflow limitations. In addition, as compared with asthma, the mean value of \%CSA $<5$ in COPD was significantly lower. Histopathologically, pulmonary vascular alterations are not exclusive to advanced COPD. They are present in patients with mild COPD and even in smokers with normal pulmonary function [3] [4]. Thus, respiratory phasic variations in the SVC may be more likely related to alterations in cardiopulmonary hemodynamics than intrathoracic pressure.

Interestingly, in patients with asthma, the i/e-SVC ratio was not significantly correlated with the \%CSA $<5, \mathrm{i} / \mathrm{e}-\mathrm{LV}$, or airflow limitation. In general, asthma is not characterized by vascular alteration, thus, cardiopulmonary hemodynamics are within normal limits. In addition, even though airflow limitation can be found to some degree, hyperinflation is not prominent during the stable status. As i/e-SVC ratio relates to hyperinflation and cardiopulmonary hemodynamics, it would not be plausible not to have significant correlations between i/e-SVC ratio and \%CSA $<5$, i/e-LV, or airflow limitation in patients with asthma. However, one might think that if asthmatic patients do not have hyperinflation or alteration in cardiopulmonary hemodynamics, i/e-SVC 
ratio should be lower than that in patients with COPD. We cannot clarify the reason for this discrepancy from the current study. There may be other factors that can affect the respiratory phasic variation of the SVC. In addition, there were some asthmatic patients who were smokers or ex-smokers in our study. Smoking causes pulmonary vascular alterations, which could also be related to these results. Although further evaluation is required, our results suggest that there are apparent differences in intrathoracic pressure and hemodynamics between asthma and COPD.

This study has some limitations. First, intrathoracic pressure was not evaluated because of the retrospective nature of the study, which is a major limitation. Although \%CSA $<5$ can indicate pulmonary arterial pressure and pulmonary perfusion [22], evaluation of cardiac function was also insufficient. Second, we did not have a control group when evaluating the differences between $\mathrm{i} / \mathrm{e}-\mathrm{SVC}$ ratios. Third, various respiratory conditions might have affected our results. Although CT scans were done both at end-inspiration and end-expiration, we cannot exclude the possibility that other respiratory maneuvers were included in the scan. In fact, flow velocity in the SVC is affected by respiratory maneuvers including tidal volume, continuous inspiration or expiration, and Valsalva maneuvers [28]. In addition, changes in the SVC would be affected by body position. Thus, findings in the present study are limited to the supine position. Fourth, we did not measure the areas of the inferior vena cava and extrathoracic veins, such as the jugular vein, because it was difficult to measure these veins on non-enhanced CT images. Determining respiratory phasic variations of those veins may contribute additional information in future studies.

\section{Conclusion}

In conclusion, even there were no significant differences in respiratory variations in the SVC area between COPD and asthma groups, these variations in the SVC area significantly correlated with hyperinflation (i/e-LV), cardiopulmonary hemodynamics (\%CSA < 5), and airflow limitation in patients with COPD, which was not observed in patients with bronchial asthma. These results suggest that there are apparent differences in the mechanisms of intrathoracic pressure and cardiopulmonary hemodynamics between COPD and bronchial asthma. This i/e-SVC ratio measurement may be useful to help clarify the pathophysiological features in obstructive diseases.

\section{Competing Interests}

The authors declare that they have no competing interests.

\section{Author's Contributions}

S. M. and T. Y. contributed to the conception and design of the study, the analysis and interpretation of the data, and the drafting of the paper. S. M., A. F., H. T, K. Y. and Y. $\mathrm{N}$. contributed to the design of the study and to revising the paper critically. All authors made final decisions on all aspects of the article and hence are in agreement with, and approve, the final version of the submitted article. 


\section{References}

[1] Nakhjavan, F.K., Palmer, W.H. and McGregor, M. (1966) Influence of Respiration on Venous Return in Pulmonary Emphysema. Circulation, 33, 8-16. https://doi.org/10.1161/01.CIR.33.1.8

[2] Cheriyan, A.F., Garrity Jr., E.R., Pifarre, R., Fahey, P.J. and Walsh, J.M. (1995) Reduced Transplant Lung Volumes after Single Lung Transplantation for Chronic Obstructive Pulmonary Disease. American Journal of Respiratory and Critical Care Medicine, 151, 851853. https://doi.org/10.1164/ajrccm/151.3_Pt_1.851

[3] Hale, K.A., Niewoehner, D.E. and Cosio, M.G. (1980) Morphologic Changes in the Muscular Pulmonary Arteries: Relationship to Cigarette Smoking, Airway Disease, and Emphysema. American Review of Respiratory Disease, 122, 273-278.

[4] Wright, J.L., Lawson, L., Pare, P.D., Hooper, R.O., Peretz, D.I., Nelems, J.M., Schulzer, M. and Hogg, J.C. (1983) The Structure and Function of the Pulmonary Vasculature in Mild Chronic Obstructive Pulmonary Disease. The Effect of Oxygen and Exercise. American Review of Respiratory Disease, 128, 702-707.

[5] Magee, F., Wright, J.L., Wiggs, B.R., Pare, P.D. and Hogg, J.C. (1988) Pulmonary Vascular Structure and Function in Chronic Obstructive Pulmonary Disease. Thorax, 43, 183-189. https://doi.org/10.1136/thx.43.3.183

[6] Barbera, J.A., Riverola, A., Roca, J., Ramirez, J., Wagner, P.D., Ros, D., Wiggs, B.R. and Rodriguez-Roisin, R. (1994) Pulmonary Vascular Abnormalities and Ventilation Perfusion Relationships in Mild Chronic Obstructive Pulmonary Disease. American Journal of Respiratory and Critical Care Medicine, 149, 423-429. https://doi.org/10.1164/ajrccm.149.2.8306040

[7] Cournand, A., Motley, H.L., Werko, L. and Richards, D.W. (1948) Physiological Studies of the Effects of Intermittent Positive Pressure Breathing on Cardiac Output in Man. American Journal of Physiology, 152, 162-174.

[8] Jörgensen, K., Houltz, E., Westfelt, U., Nilsson, F., Scherstén, H. and Ricksten, S.E. (2003) Effects of Lung Volume Reduction Surgery on Left Ventricular Diastolic Filling and Dimensions in Patients with Severe Emphysema. Chest, 124, 1863-1870. https://doi.org/10.1378/chest.124.5.1863

[9] Jörgensen, K., Müller, M.F., Nel, J., Upton, R.N., Houltz, E. and Ricksten, S.E. (2007) Reduced Intrathoracic Blood Volume and Left and Right Ventricular Dimensions in Patients with Severe Emphysema: An MRI Study. Chest, 131, 1050-1057. https://doi.org/10.1378/chest.06-2245

[10] Watz, H., Waschki, B., Meyer, T., Kretschmar, G., Kirsten, A., Claussen, M. and Magnussen, H. (2010) Decreasing Cardiac Chamber Sizes and Associated Heart Dysfunction in COPD: Role of Hyperinflation. Chest, 138, 32-38. https://doi.org/10.1378/chest.09-2810

[11] Smith, B.M., Kawut, S.M., Bluemke, D.A., Basner, R.C., Gomes, A.S., Hoffman, E., Kalhan, R., Lima, J.A., Liu, C.Y., Michos, E.D., Prince, M.R., Rabbani, L., Rabinowitz, D., Shimbo, D., Shea, S. and Barr, R.G. (2013) Pulmonary Hyperinflation and Left Ventricular Mass: The Multi-Ethnic Study of Atherosclerosis COPD Study. Circulation, 127, 1503-1511. https://doi.org/10.1161/CIRCULATIONAHA.113.001653

[12] Guyton, A.C., Lindsey, A.W., Abernathy, B. and Richerardson, T. (1957) Venous Return at Various Right Atrial Pressures and the Normal Venous Return Curve. American Journal of Physiology, 189, 609-615.

[13] Robotham, J.L., Lixfeld, W., Holland, L., MacGregor, D., Bromberger-Barnea, B., Permutt, S. and Rabson, J.L. (1980) The Effects of Positive End-Expiratory Pressure on Right and 
Left Ventricular Performance. American Review of Respiratory Disease, 121, 677-683.

[14] Izumi, S., Moriyama, K., Kobayashi, S., Toda, H., Ohta, T., Matsuno, Y., Shimada, T., Murakami, R. and Morioka, S. (1994) Phasic Venous Return Abnormality in Chronic Pulmonary Diseases: Pulsed Doppler Echocardiography Study. Internal Medicine, 33, 326-333. https://doi.org/10.2169/internalmedicine.33.326

[15] Kimura, B.J., Dalugdugan, R., Gilcrease, G.W., Phan, J.N., Showalter, B.K. and Wolfson, T. (2011) The Effect of Breathing Manner on Inferior Vena Caval Diameter. European Journal of Echocardiography, 12, 120-123. https://doi.org/10.1093/ejechocard/jeq157

[16] Wexler, L., Bergel, D.H., Gabe, I.T., Makin, G.S. and Mills, C.J. (1968) Velocity of Blood Flow in Normal Human Venae Cavae. Circulation Research, 23, 349-359. https://doi.org/10.1161/01.RES.23.3.349

[17] Natori, H., Tamaki, S. and Kira, S. (1979) Ultrasonographic Evaluation of Ventilatory Effect on Inferior Vena Caval Configuration. American Review of Respiratory Disease, 120, 421427.

[18] Grant, E., Rendano, F., Sevinc, E., Gammelgaard, J., Holm, H.H. and Grønvall, S. (1980) Normal Inferior Vena Cava: Caliber Changes Observed by Dynamic Ultrasound. American Journal of Roentgenology, 135, 335-338. https://doi.org/10.2214/ajr.135.2.335

[19] Matsuoka, S., Yamashiro, T., Kotoku, A., Matsushita, S., Fujikawa, A., Yagihashi, K., Kurihara, Y. and Nakajima, Y. (2015) Changes in the Superior Vena Cava Area during Inspiration and Expiration in Relation to Emphysema. COPD: Journal of Chronic Obstructive Pulmonary Disease, 12, 168-174. https://doi.org/10.3109/15412555.2014.922171

[20] Blaustein, A.S., Risser, T.A., Weiss, J.W., Parker, J.A., Holman, B.L. and McFadden, E.R. (1986) Mechanisms of Pulsus Paradoxus during Resistive Respiratory Loading and Asthma. Journal of the American College of Cardiology, 8, 529-536. https://doi.org/10.1016/S0735-1097(86)80179-6

[21] Yamashiro, T., Matsuoka, S., Bartholmai, B.J., San Jose Estepar, R., Ross, J.C., Diaz, A., Murayama, S., Silverman, E.K., Hatabu, H. and Washko, G.R. (2010) Collapsibility of Lung Volume by Paired Inspiratory and Expiratory CT Scans: Correlations with Lung Function and Mean Lung Density. Academic Radiology, 17, 489-495.

https://doi.org/10.1016/j.acra.2009.11.004

[22] Matsuoka, S., Washko, G.R., Yamashiro, T., Estepar, R.S., Diaz, A., Silverman, E.K., Hoffman, E., Fessler, H.E., Criner, G.J., Marchetti, N., Scharf, S.M., Martinez, F.J., Reilly, J.J. and Hatabu, H. (2010) Pulmonary Hypertension and Computed Tomography Measurement of Small Pulmonary Vessels in Severe Emphysema. American Journal of Respiratory and Critical Care Medicine, 181, 218-225. https://doi.org/10.1164/rccm.200908-1189OC

[23] Appleton, C.P., Hatle, L.K. and Popp, R.L. (1987) Superior Vena Cava and Hepatic Vein Doppler Echocardiography in Healthy Adults. Journal of the American College of Cardiology, 10, 1032-1039. https://doi.org/10.1016/S0735-1097(87)80343-1

[24] Brecher, G.A. and Mixter Jr., G. (1953) Effect of Respiratory Movements on Superior Cava Flow Under Normal and Abnormal Conditions. American Journal of Physiology, 172, 457461.

[25] Brecher, G.A. and Hubay, C.A. (1955) Pulmonary Blood Flow and Venous Return during Spontaneous Respiration. Circulation Research, 3, 210-214.

https://doi.org/10.1161/01.RES.3.2.210

[26] Santamore, W.P. and Amoore, J.N. (1994) Buffering of Respiratory Variations in Venous Return by Right Ventricle: A Theoretical Analysis. American Journal of Physiology, 267, H2163-H2170. 
[27] Bogaard, H.J., Dekker, B.M., Arntzen, B.W., Woltjer, H.H., van Keimpema, A.R., Postmus, P.E. and de Vries, P.M. (1998) The Haemodynamic Response to Exercise in Chronic Obstructive Pulmonary Disease: Assessment by Impedance Cardiography. European Respiratory Journal, 12, 374-379. https://doi.org/10.1183/09031936.98.12020374

[28] Tschernko, E.M., Gruber, E.M., Jaksch, P., Jandrasits, O., Jantsch, U., Brack, T., Lahrmann, H., Klepetko, W. and Wanke, T. (1998) Ventilatory Mechanics and Gas Exchange during Exercise before and after Lung Volume Reduction Surgery. American Journal of Respiratory and Critical Care Medicine, 158, 1424-1431.

https://doi.org/10.1164/ajrccm.158.5.9702086

Submit or recommend next manuscript to SCIRP and we will provide best service for you:

Accepting pre-submission inquiries through Email, Facebook, LinkedIn, Twitter, etc.

A wide selection of journals (inclusive of 9 subjects, more than 200 journals)

Providing 24-hour high-quality service

User-friendly online submission system

Fair and swift peer-review system

Efficient typesetting and proofreading procedure

Display of the result of downloads and visits, as well as the number of cited articles

Maximum dissemination of your research work

Submit your manuscript at: http://papersubmission.scirp.org/

Or contact ojmi@scirp.org 